Archives de sciences sociales des religions

114 | avril-juin 2001

Varia

\title{
ADORNO (Theodor W.), Sur Walter Benjamin
}

Paris, Éditions Allia, 1999 (trad. par Christophe David), 175 p.

Michael Löwy

\section{OpenEdition}

\section{Journals}

Édition électronique

URL : http://journals.openedition.org/assr/20836

DOI : $10.4000 /$ assr.20836

ISSN : 1777-5825

Éditeur

Éditions de l'EHESS

Édition imprimée

Date de publication : 1 juin 2001

Pagination : 123-124

ISBN : 2-222-96704-X

ISSN : 0335-5985

Référence électronique

Michael Löwy, «ADORNO (Theodor W.), Sur Walter Benjamin», Archives de sciences sociales des religions [En ligne], 114 | avril-juin 2001, document 114.49, mis en ligne le 19 août 2009, consulté le 10 décembre 2020. URL : http://journals.openedition.org/assr/20836 ; DOI : https://doi.org/10.4000/ assr.20836

Ce document a été généré automatiquement le 10 décembre 2020.

(c) Archives de sciences sociales des religions 


\section{ADORNO (Theodor W.), Sur Walter Benjamin}

Paris, Éditions Allia, 1999 (trad. par Christophe David), 175 p.

\section{Michael Löwy}

\section{RÉFÉRENCE}

ADORNO (Theodor W.), Sur Walter Benjamin, Paris, Éditions Allia, 1999 (trad. par Christophe David), 175 p.

1 Ce recueil rassemble tous les textes de T.W.A. dédiés à l'œuvre de son ami Benjamin au cours des années cinquante et soixante, ainsi que quelques extraits de lettres des années trente. L'ensemble témoigne de la sympathie et des liens d'affinité élective entre les deux intellectuels juifs allemands exilés par le nazisme, mais aussi de leurs divergences et, parfois, de certains malentendus.

Commençons, pour suivre un ordre chronologique, par la deuxième partie du livre, qui contient certaines des lettres adressées par T.W.A., au cours des années 1934-1939, à son ami exilé à Paris. Un des aspects les plus frappants de ces documents est la place essentielle qu'occupe, surtout dans les lettres de 1934-1935, la théologie juive. Par exemple, dans une lettre qui commente l'essai de Benjamin sur Kafka, Theodor Wisegrund - c'était son nom juif, celui de son père - se réfère à ce qu'il désigne comme «notre théologie», une théologie «inversée » qui permet de comprendre l'œuvre de Kafka comme " une photographie de l'existence terrestre du point de vue de ceux qui ont été sauvés ». Le parallèle est frappant avec ce que Gershom Scholem désigne, dans sa propre correspondance avec Walter Benjamin, comme la «théologie négative » de Kafka. Les trois penseurs semblent se retrouver - sans que T.W.A. connaisse les lettres de Scholem, et vice-versa - sur une interprétation théologique de Kafka qui prend le contre-pied de celle, optimiste et " positive ", de son ami et éditeur Max Brod.

Dans une lettre de 1935, commentaire de l'essai de Benjamin sur «Paris, capitale du XIX siècle », on trouve une sorte de proposition programmatique: la théorie 
philosophique ne peut trouver sa dialectique que dans la polarité des catégories sociales et théologiques. Dans cet esprit, T.W.A. suggère à son ami de "restituer la théologie ou plutôt de radicaliser la dialectique jusqu'en son foyer théologique ardent " - un conseil que Benjamin va suivre à la lettre, mais seulement cinq années plus tard, dans son testament philosophique, les thèses "Sur le concept d'histoire ", rédigées peu avant son suicide à la frontière franco-espagnole (1940).

Cette thématique théologique n'est pas absente des écrits que T.W.A. va dédier au cours des années cinquante et soixante à la pensée de son ami, mais elle prend ici une tournure nouvelle, fortement marquée par l'exigence de sécularisation. Il part de l'hypothèse suivante : une philosophie du langage inspirée de la kabbale - dont il avait pris connaissance grâce aux travaux sur la mystique juive de G. Scholem - est ce qui relie les écrits théologiques de jeunesse de Walter Benjamin avec ceux, matérialistes, des années trente. Sa méthode, empruntée au modèle théologique et mystique juif d'exégèse biblique, consiste à traiter des textes profanes comme s'ils étaient des textes sacrées. Il avait compris qu'une sécularisation/profanation radicale était la seule chance de sauver l'héritage théologique.

5 Curieusement, la dimension messianique de la philosophie de Benjamin est peu présente dans les commentaires de T.W.A., sauf dans un texte tardif, de 1969, qui résume dans un raccourci lumineux la démarche théologico-politique de son ami : dans la tradition du messianisme juif, sa conception de l'utopie est fondée sur l'idée que la rédemption est intramondaine et coïncide avec l'émancipation sociale. On ne saurait mieux rendre compte, en une seule phrase, du «foyer ardent» où l'utopie révolutionnaire et la rédemption messianique se rencontrent et fusionnent dans la philosophie hérétique, juive et marxiste, de Walter Benjamin. 